Indonesian Journal of Physics and Nuclear Applications

Volume 3, Number 1, February 2018, p. 21-28

e-ISSN 2550-0570, (C FSM UKSW Publication

\title{
Manufacture of Nickel Collimator for BNCT: Smelting of Nickel Using Electrical Arc Furnace and Centrifugal Casting Preparation
}

\author{
Mujiyono $^{1)}$, Suharto ${ }^{2)}$, Fajar Nurjaman ${ }^{2)}$, Alaya Fadllu Hadi Mukhammad ${ }^{3)}$, \\ Didik Nurhadiyanto ${ }^{1)}$, Arianto Leman Sumowidagdo ${ }^{1)}$ \\ ${ }^{1)}$ Engineering Faculty of Yogyakarta State University, Indonesia \\ ${ }^{2)}$ UPT Balai Pengolahan Mineral Lampung (UPT BPML)-LIPI, Indonesia \\ ${ }^{3)}$ Engineering Faculty of Diponegoro University, Indonesia \\ Email: mujiyonouny@yahoo.com
}

\begin{abstract}
Collimator is a tube that functions to direct neutrons generated by a nuclear reactor for BNCT (Boron Neutron Capture Therapy Cancer). Appropriate design of the collimator for BNCT application is a tube with an inner diameter of $16 \mathrm{~cm}$, an outer diameter of $19 \mathrm{~cm}$ and a length of $13 \mathrm{~cm}$ total with 12 pieces with nickel purity above $95 \%$. Manufacturing of the BNCT collimator will be planned using centrifugal casting method and smelting of nickel with electrical arc (EA) furnace. This article reports on the smelting process of nickel, setting the parameters of the electrical arc furnace, and the chemical composition of the nickel. Results of the study show that nickel with purity $98 \%$ can be melted perfectly using the EA Furnace with a current of 600-800 A and a pouring temperature of $1600^{\circ} \mathrm{C}$. The fluidity of nickel can hold up to 1 minute at a $35^{\circ} \mathrm{C}$ environment that allows for the centrifugal casting process. The chemical composition of the nickel before being melted is $\mathrm{Ni}(98.89 \%), \mathrm{Si}(0.79 \%), \mathrm{S}(0.17 \%)$, and $\mathrm{Fe}(0.15 \%)$ and after being melted is $\mathrm{Ni}(97.89 \%), \mathrm{Si}(0.92 \%), \mathrm{S}(0.26 \%)$, and $\mathrm{Fe}(0.90 \%)$. The chemical composition of the nickel after smelting in an EA Furnace meets the requirements of BNCT collimator.
\end{abstract}

Keywords nickel, BNCT collimator, electrical arc furnace, chemical composition

\section{INTRODUCTION}

The research is manufacturing of BNCT collimator from nickel of at least $95 \% \mathrm{Ni}$. The collimator is a tube with an inner diameter of $160 \mathrm{~mm}$, an outer diameter of $190 \mathrm{~mm}$, and a length of $130 \mathrm{~mm}$. Number of the tube is 12 pieces which are connected so that the total length is $1560 \mathrm{~mm}$. The Collimator must be free from defects in materials such as porosity and inclusions. Nickel has a solid density of $8.9 \mathrm{~g} / \mathrm{cm}^{3}$, the liquid density $7.8 \mathrm{~g} / \mathrm{cm}^{3}$, melting point of $1455^{\circ} \mathrm{C}$ and a boiling point of $2913^{\circ} \mathrm{C}$, heat of fusion is $17.48 \mathrm{~kJ} / \mathrm{mol}$, heat of vaporization is $377.5 \mathrm{~kJ} / \mathrm{mol}$, and heat of capacity is $26.1 \mathrm{~J} / \mathrm{mol} . \mathrm{K}$. Nickel is a silvery white metal, shiny, hard, and has a crystal structure of face center cubic (fcc) with a malleable nature and can be manufactured by a casting process. Nickel does not react with alkaline bases (Davis, 2001).

The main challenge is to produce a pure nickel smelting method that is able to maintain the chemical composition that the BNCT collimator requires. Electric Arc Furnaces (EA Furnace) is one furnace that can be used for pure nickel. The electrically conductive properties of 
nickel are unfavorable and motivate the use of an arc furnace to melt pure nickel. Jones (2013) succeeded in using a DC arc furnace for smelting reductive for the recovery of nickel. This paper reports that EA Furnace should be used to smelt pure nickel and analyze chemical composition changes. Then smelting of the pure nickel is used as the basis for manufacturing and planning a tube for the collimator at BNCT with the centrifugal casting method. Gravity casting method is not selected, although this casting has been used by many small industries, because this method has a high potential for defects, including defects of porosity or air voids, defects of flow and shrinkage cavity defects. This was caused by the need for getting a complex system and molding sand systems which are relatively weak. So, the centrifugal casting method was chosen and planned to manufacture collimator for BNCT made from pure nickel.

\section{METHODOLOGY}

This study is in the initial stage of the manufacturing process of BNCT collimator from pure nickel with composition requirements of at least $95 \% \mathrm{Ni}$. So, the research only studied the smelting process of pure nickel with a purity of $98 \%$ using the EA Furnace. Then the nickel was analyzed and the chemical composition using X-ray fluorescence was compared to requirements of BNCT collimator. Results of this study were then used as the basis for planning the centrifugal casting method to be implemented for manufacturing the tube of BNCT collimator.

\section{Materials}

The material used in this study was nickel with a purity of $98.9 \%$ and a square form with 2 group sizes of $15 \times 15 \mathrm{~cm}^{2}$ and $3 \times 3 \mathrm{~cm}^{2}$ as shown in Figure 1. Smelting process was done 2 times by inserting each group into the furnace chamber of EA Furnace. The results of the smelting of nickel were then analyzed and the chemical composition was determined by X-ray Fluorescence Type 6000-C Delta Standard, Olympus.

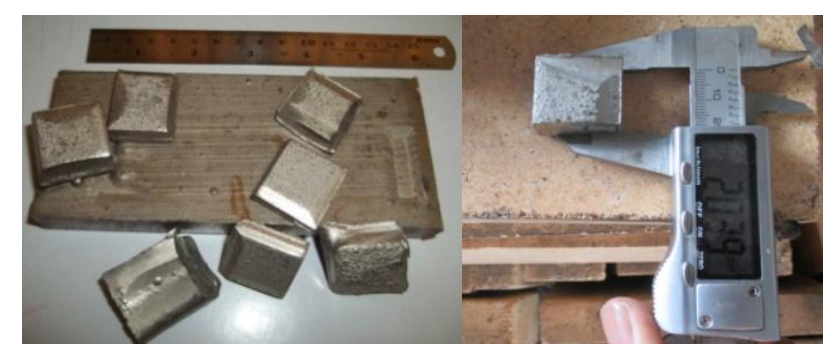

Figure 1. Pure nickel as basic material of BNCT collimator

\section{Research Equipment}

The main equipment of the study was an Electric Arc Furnace with specifications as in Table 1 and temperature work up to $1800^{\circ} \mathrm{C}$. The source of the furnace uses 3 phase types with 3 graphite electrodes by a transformer "stepdown". This electrode has a diameter of $3 \mathrm{~cm}$ and a length of $27 \mathrm{~cm}$ as shown in Figure 2. This furnace has a constant voltage characteristic that the current can be changed according to arc that works with a constant voltage. So, the arc of each electrode is electrified at 800 - 2000 A with a fixed voltage of 65 volts. This furnace is suitable for metals with good electrical conductive properties. 
Table 1. Specification of Electric Arc Furnace

\begin{tabular}{|c|c|}
\hline Capacity & $100 \mathrm{Kg} / \mathrm{Heat}$ \\
\hline Total electrodes & 3 pieces \\
\hline Electrode & Diameter $30 \mathrm{~mm}$, Length $80 \mathrm{~cm}$ \\
\hline Electrical Power & Øin $41.5 \mathrm{kVA}, 65$ Volt height $27 \mathrm{~cm}$ \\
\hline Furnace chamber & up to $1500 \mathrm{~A}$ \\
\hline Electrical current & \\
\hline
\end{tabular}

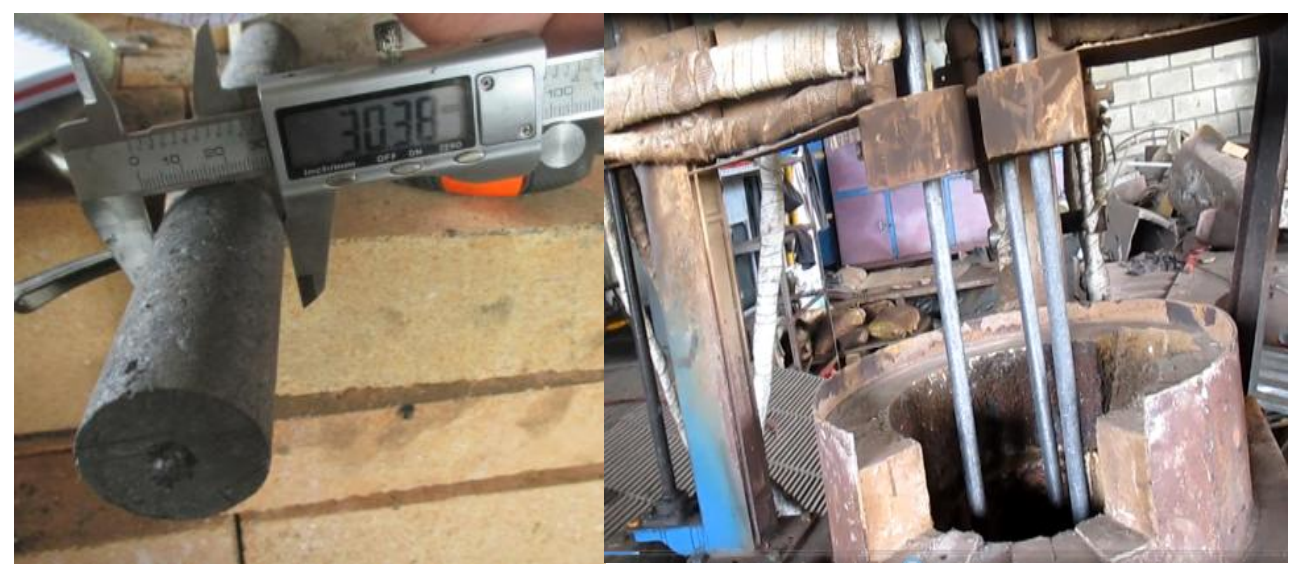

Figure 2. Graphite Electrodes and Electric Arc Furnace with 3 graphite electrodes

\section{RESULTS AND DISCUSSION \\ Smelting Process of Pure Nickel}

Nickel with a dimension of $15 \times 15 \mathrm{~cm} 2$ cannot be melted completely in the EA Furnace. Smelting of nickel occurred only around the graphite electrode as shown in Figure 3. The phenomena occurred because the arc is a vector, where the heat only occurs in one direction so the melting shape of the nickel is a $3 \mathrm{~cm}$ hole in diameter at the graphite electrodes and the nickel in the direction perpendicular to the electrodes cannot melt because there was inadequate heat. Therefore the effective dimension for the nickel in order to perfect the smelting is equal to the diameter of the graphite electrode.

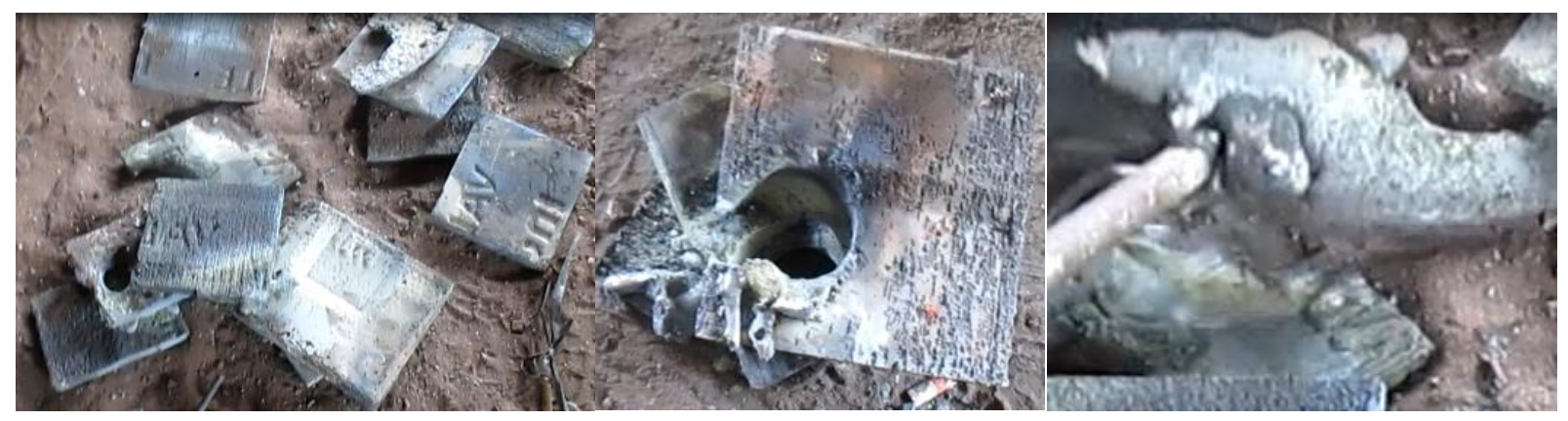

Figure 3. Nickel Dimension of $15 \times 15 \mathrm{~cm} 2$ can't melt perfectly in EA Furnace 
Consolidation was then performed using the nickel dimension group 2 which was $3 \times 3$ $\mathrm{cm}^{2}$ and a thickness of $3 \mathrm{~cm}$ as shown in Figure 1. The smelting was done by setting the EA Furnace on voltage 65 volts whichproduced an arc with current 1000-1800 amperage. The results showed that the nickel can be melted perfectly in EA Furnace as shown in Figure 4.

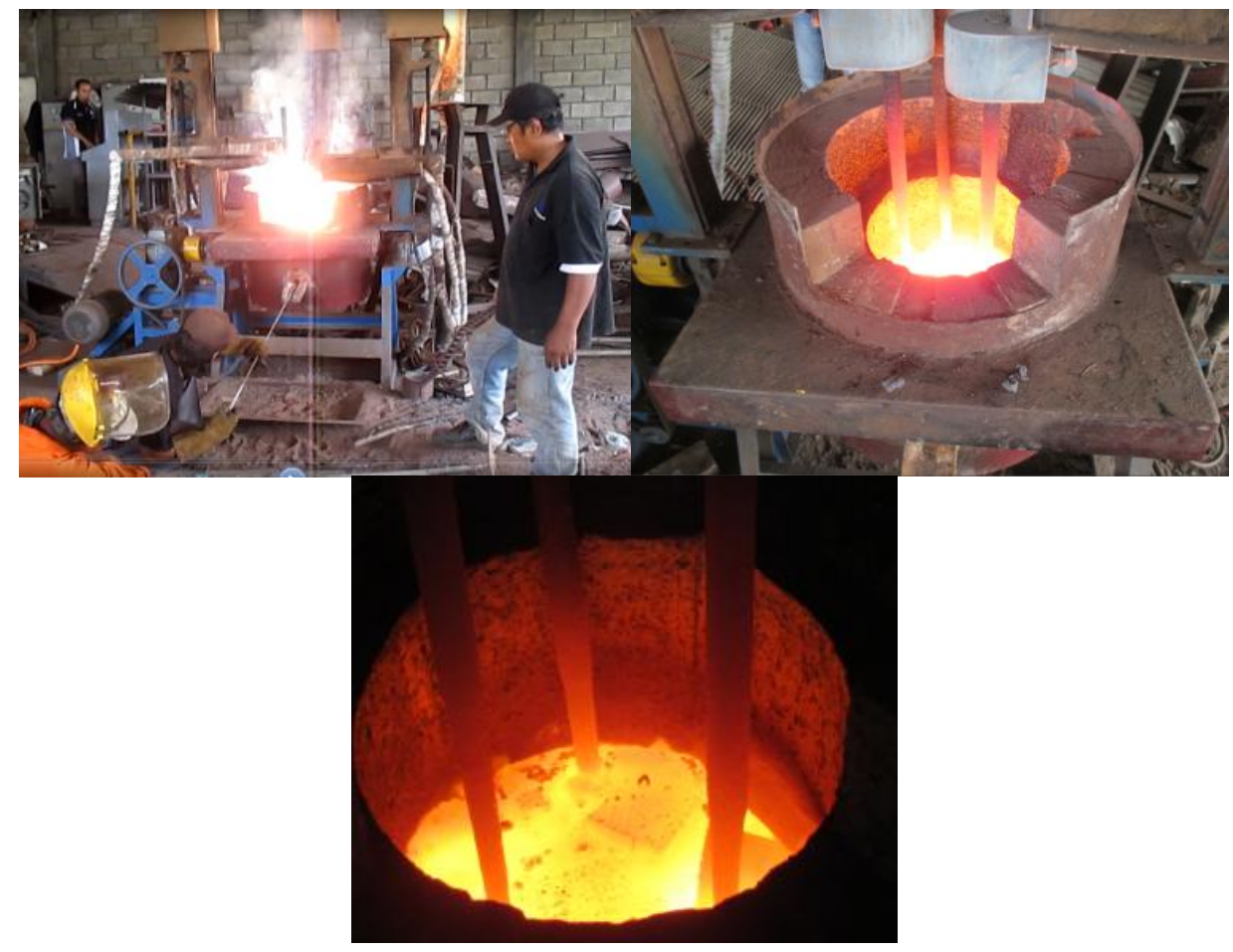

Figure 4. Nickel dimensions of $3 \times 3 \mathrm{~cm}^{2}$ can melt perfectly in EA Furnace

Nickel liquid was then removed from the furnace chamber and poured into a molding as shown in Figure 5. The mold was 3 meters from the EA Furnace and the nickel still had a good fluidity for 1 minute at an ambient temperature of $35^{\circ} \mathrm{C}$, so it has the potential to be manufactured using the centrifugal casting method.

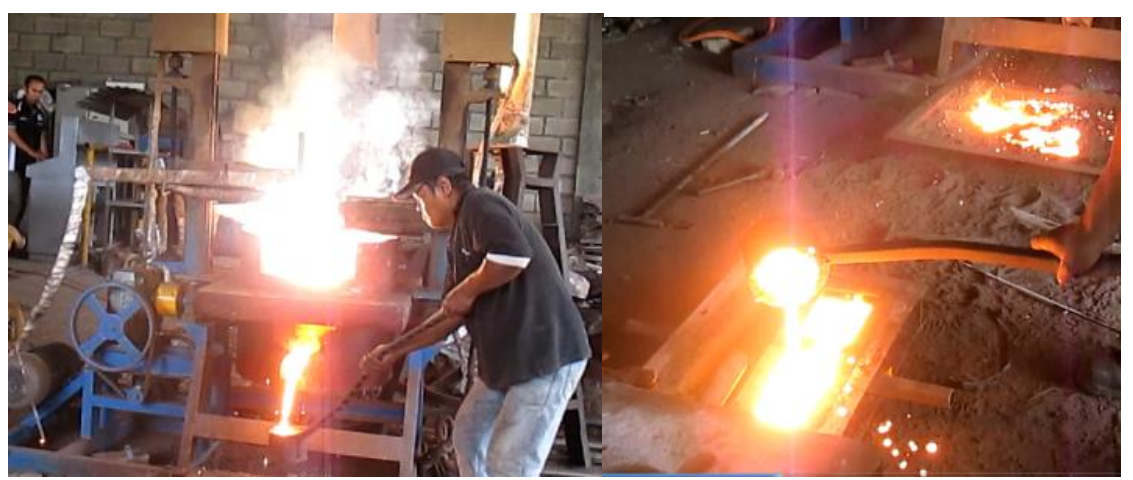

Figure 5. The discharge process of nickel from the furnace chamber and pouring it into the molding 


\section{Chemical Composition of Nickel}

The chemical composition of nickel before and after the casting process didn't change significantly as shown in Table 2 . The major changes in the composition of the nickel were a decrease of $1 \%$ from $98.89 \%$ to $97.89 \%$ as a result of the addition of $0.75 \%$ Fe, Si $12: 13 \%$ and $00: 09 \% \mathrm{~S}$. The purity of the nickel is still eligible for BNCT collimator by $95 \%$. Another significant addition is the element carbon, but it was not detected by XRF. The addition of carbon was predicted from EA Furnace electrodes that are made of graphite, but carbon doesn't affect the function of the BNCT collimator in directing the neutron so it is feasible to manufacture the collimator by centrifugal casting.

Table 2. The chemical composition of nickel before and after the casting process

\begin{tabular}{|c|c|c|c|c|c|c|c|c|}
\hline \multirow{2}{*}{ Element } & \multicolumn{3}{|c|}{ Before casting } & \multirow{2}{*}{ average } & \multicolumn{3}{|c|}{ After casting } & \multirow{2}{*}{ average } \\
\hline & Qty & Qty & Qty & & Qty & Qty & Qty & \\
\hline $\mathrm{Ni}(\%)$ & 99.08 & 98.94 & 98.65 & 98.89 & 97.75 & 97.88 & 98.04 & 97.89 \\
\hline $\mathrm{Si}(\%)$ & 0.72 & 0.85 & 0.81 & 0.79 & 0.45 & 0.64 & 1.68 & 0.92 \\
\hline $\mathrm{S}(\%)$ & 0.15 & 0.15 & 0.21 & 0.17 & & 0.34 & 0.17 & 0.26 \\
\hline $\mathrm{Fe}(\%)$ & 0.05 & 0.06 & 0.33 & 0.15 & 1.47 & 1.14 & 0.09 & 0.90 \\
\hline
\end{tabular}
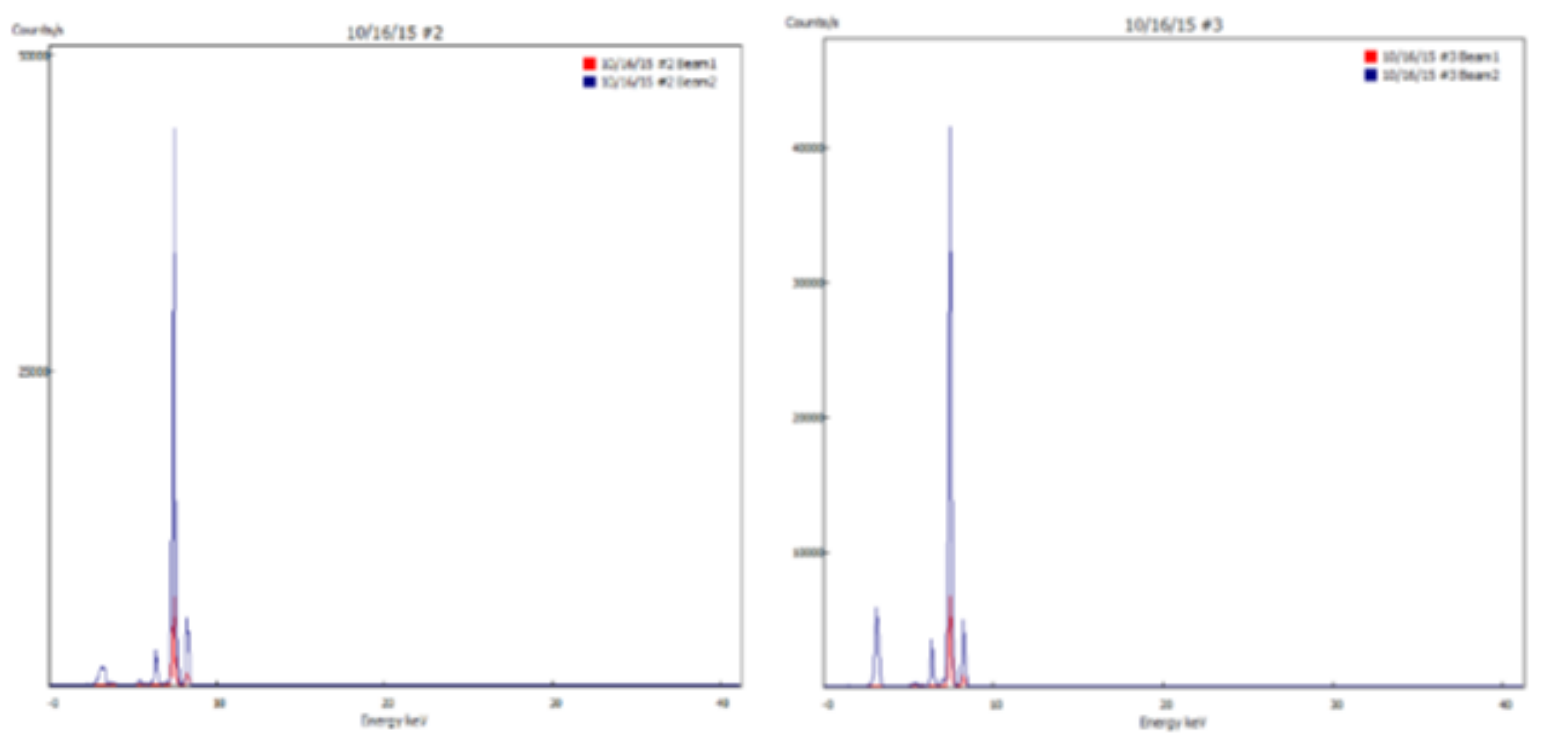

Figure 6. XRF results of nickel chemical composition before and after the casting process 


\section{Potential of Centrifugal Casting Method for Manufacturing of BNCT Collimator}

Centrifugal casting is a casting technique in which molten metal is poured into a mold that is rotating (ASM Handbook, 1998). This method utilizes rotation to generate a centrifugal force. The centrifugal force produced by the rotation of the mold will cause the molten metal that is poured to push away from the axis of rotation and toward the fingers furthest from the mold and produce a more complete filling of the mold cavity (Jorstad, 1993). Some favorable characteristics of centrifugal casting are that the casting products are relatively uniform, it does not require a riser, it has a high density, especially on the outer castings, and there's no shrinkage, especially on the outside of the cast due to the centrifugal force working continuously during the freezing process. Impurities of centrifugal casting products occur on the inner wall of the casting and can be removed by machining. Drawbacks of the centrifugal casting process include the price of the expensive equipment, the high maintenance costs, the requirement of a large centrifugal force, and a low production rate as the mold is only used for one product. Banga et al, (1981) reported that centrifugal casting has several advantages. The First, better quality castings because pressure from the centrifugal force is generated when the molten metal solidifies. The second, it is more economical than the other way, because it is not necessary to get a system. Third, impurities and slag can be gathered at the center of the casting and can be removed by machining.
The Strength of centrifugal force (Joshi, 2002) which occurs at a specific point in the cross sectional position is as follows:

$$
C F=\frac{m v^{2}}{r} \text { or }(\omega r)^{2}=m \omega^{2} r \ldots \ldots \ldots .(1)
$$

By, $\mathrm{m}=\operatorname{mass}(\mathrm{kg}), \mathrm{r}=\operatorname{radius}(\mathrm{m}) \cdot \mathrm{v}=$ peripheral speed $(\mathrm{m} / \mathrm{s}), \omega=$ angular rotational speed. ( $\mathrm{rad} / \mathrm{s})$.

Gravitational Force, GF = mg............(2).Where, $\mathrm{g}=$ acceleration due to gravity (m/ s2). Coefficient of gravity (C factor) is;

Gfactor $=\frac{C \cdot F}{G . F}=\frac{m v^{2}}{r \cdot m \cdot g}=\frac{v^{2}}{r \cdot g}$

Rotational speed range 50-100 G for metal mold (metal mold) and 25-50 G for molding sand (sand cast). Speed is too high causing excess stress and the resulting heat tears on the outside surface of the casting.

Horizontal centrifugal casting $\mathrm{N}=\frac{30}{\pi} \sqrt{\frac{2 \cdot \text { g.G }}{\text { Do }}}$ (4).

The centrifugal force also causes freezing to occur on the fingers of the outer mold toward the spin axis molds, which will produce a more ideal directional solidification than static casting. Good microstructure and density will enhance the mechanical properties of the product (Jostrad, 1993). The centrifugal casting also has some negative sides. With the pressure on the molten metal, the mold used must be able to withstand the pressure of the molten metal in order to prevent the mold from breaking during the casting process. The pressure on the liquid metal also causes the liquid metal to flow at a rate much higher than gravity casting. This high flow rate will cause an increased erosion rate in the metal flow. This requires the mold to have a surface resistance strong enough to withstand erosion due to the flow of metal. Narrowing of 
the liquid metal channel functions as an addition to the flow rate, so that creating an object that has many thin sections will require a strong mold.

Horizontal centrifugal casting is generally used in the manufacture of pipeline tubes, bushings, liner and some components are cylindrical with a relatively simple shape (ASM Handbook, 1998). Yan et al (2012) conducted research on the production of hollow rod continuous cast iron by using vertical centrifugal casting. The test results showed that the resulting product has a high density, low shrinkage defects, and small porosity. The Brinell hardness test showed hardness gradation of casting product, increasingly more hardness on the outside diameter than the inner diameter (Situngkir, 2009). That the Brinell hardness on the outside diameter was higher than the inner diameter shows that the density is increased.

\section{Design and Manufacturing of Centrifugal Casting Machine}

High potential of centrifugal casting (CC) are designed for manufacturing BNCT collimator. The design of CC machine as shown in Figure 7.
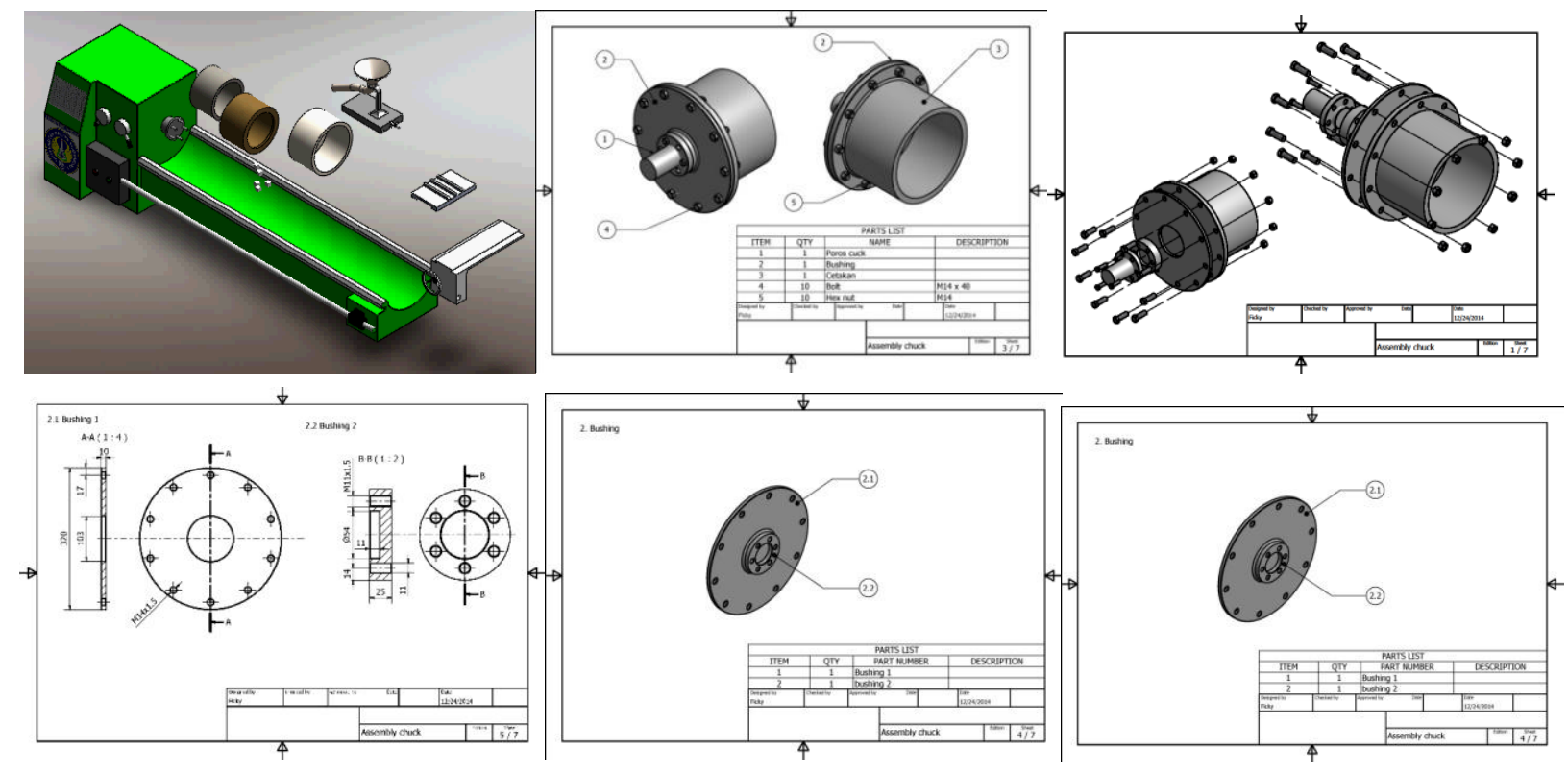

Figure 7. Design of centrifugal casting machine

The design of Centrifugal casting machine was successfully realized using a rotational speed up to $2200 \mathrm{rpm}$ as shown in Figure 8 and tested for casting. Products of casting from the machine, i.e. porosity and inclusion in inner diameter of the tube and can be removed by the lathe machine process. Furthermore, this machine is planned to manufacture pure nickel tube for BNCT collimator with purity above $95 \% \mathrm{Ni}$. 


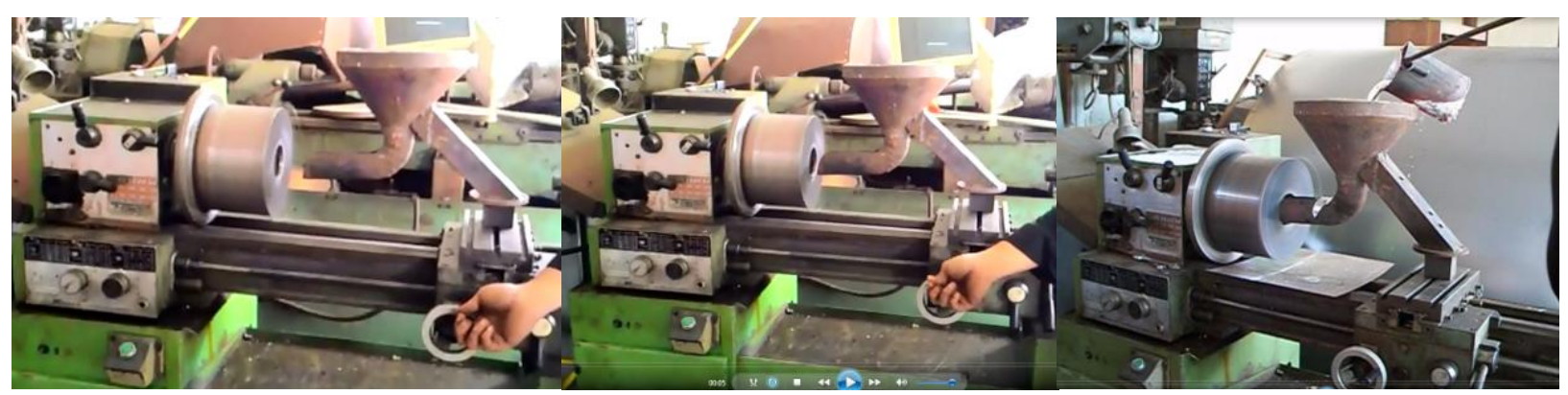

Figure 8. Centrifugal casting machine

\section{CONCLUSION}

1. Electric Arc Furnace can be used for smelting process of $98 \%$ nickel purity.

2. The chemical composition of $98 \%$ nickel is relatively constant in EA Furnace which meets the requirement of the BNCT collimator.

3. The centrifugal casting method has a high potential to manufacture BNCT collimator.

\section{REFERENCES}

ASM Handbook. 1998. Casting Volume 15. ASM International Handbook Committee.

Banga, T.R..Agarwal.R.L..Manghnani.T.. 1981. Foundry Engineering.KhannaPublisshers. Delhi.

Davis, J.R. (2001). ASM Specialty Handbook: Nickel, Cobalt, and Their Alloy. ISBN-13: 9780871706850. Publisher: ASM International; Upd Sub edition January 15, 2001.

Jones, R.T. (2013). Reductive Smelting for the Recovery of Nickel in a DC Arc furnace.Proceedings of EMC 2013.Mintek. 200 Malibongwe Drive. Randburg, South Africa

Jorstad. John. L.. Rasmussen. Wayne. M.. 1993. Aluminum Casting Technology. U.S.A: American Foundrymen's Society. Inc.

Joshi.A.M.. 2002. Aluminium Foundry Practice. Dept.Of Metallurgical Engg.And Material Science.Indian Institute of Technology Bombay. India.

Situngkir, H. 2009. Pengaruh Putaran Cetakan Terhadap Sifat Mekanik Besi Cor Kelabu Pada Pembuatan Silinder Liner Mesin Otomotif Dengan Pengecoran Sentrifugal Mendatar. Jurnal Dinamis Vol. II, No. 4

Yan, Guojun., Yang Xu, Bailing Jiang. The production of high-density hollow cast-iron bars by vertically continuous casting. Journal of Materials Processing Technology 212 (2012) 15-18 